\title{
Towards a framework to enable the migration process to educational clouds in Saudi higher education
}

\author{
Abdulrahman Alharthi, Madini O. Alassafi, Robert J Walters and Gary B Wills \\ School of Electronics and Computer Science \\ University of Southampton \\ Southampton, United Kingdom \\ \{aaa2g14, moa2g15, rjw1, gbw \}@ soton.ac.uk
}

\begin{abstract}
Nowadays, Universities have become more reliant on Information and Communication Technology (ICT) to provide educational services for their stakeholders. While most of the Universities in Europe and North America has harnessed the capabilities of cloud services to provide large scale flexibly electronic educational services. In Saudi Arabia, most of the Universities are start-ups with limited IT Staff and ICT infrastructure. Therefore, migrating their ICT services to cloud computing could deliver substantial benefits in the form of rich education content, increased efficiency, and agility that can be used to transform higher education in Saudi universities. However, to successfully migrate to the cloud in the Saudi universities context, it is essential to identify the enabler factors that contribute toward a successful migration to the cloud environment in the higher education settings. Therefore, this research paper proposes a framework to investigate technological and organizational success factors that enable the migration process of the Saudi Universities' ICT to the cloud environment.
\end{abstract}

Keywords-Cloud Computing; Cloud Migration; Success factors.

\section{INTRODUCTION}

Cloud computing is a model for enabling convenient, ondemand network access to a shared pool of configurable computing resources (e.g., networks, servers, storage, applications and services) that can be rapidly provisioned and released with minimal management effort or service provider interaction. This IT as utility paradigm was a dream of McCarthy back in 1960s [1]. In recent Years, advances in the Internet bandwidth have accelerated the use of cloud-based services by higher education institutions to supply their stakeholders with agile, scalable and on demand online educational services [2]. Cloud computing offers several benefits for the educational institutions as follows: (1) Hardware cost reduction as the cloud is On-demand and "payper-use" fashion, it is more beneficial for universities than the investment of an expensive and limited infrastructure, as the utilization of such an infrastructure might be very low at certain times during the academic year [3]. (2) Scalable Storage and Sharing as Learning outcomes and resources can be stored in the cloud, which provides almost unlimited store and computation capacities. Documents can be commonly edited and shared in the cloud, some of the Public sharing services are provided by Google docs, live SkyDrive, and Office Live [4], (3) Universal access to the computational resources, as the learners can study and access the resources anywhere, anytime and from any device without setup efforts [5], [6].

In developed countries, the universities have adopted the cloud increase service efficiency and cost-savings. An example from the University of California (UC) at Berkeley, found cloud computing to be attractive for use in one of their courses which was focused exclusively on developing and deploying Software as a service (SaaS) applications[2], [5]. The Medical College of Wisconsin Biotechnology and Bioengineering Centre in Milwaukee found the use of cloud computing in their research has provided an astounding computing power. Researchers at the center have been doing protein research which has been made more accessible to scientists from anywhere in the world. This is due largely to renting Google's cloud-based servers. Some universities have adopted cloud computing for economic reasons. The Washington State University's School of Electrical Engineering and Computer Science (EECS) has suffered cuts in its budget. However, the EECS claims that despite the challenging economic climate, cloud computing has actually enabled it to expand the services it offers to faculties and students [2], [7]. The usage of cloud services in UK and European universities is growing dramatically in comparison with the Saudi universities. The Saudi University has just begun the initial phase in order to offer teaching through cloud 
computing [8]. Many industry experts believe that cloud computing will be widely used in higher education [9]. At the same time, it is important to understand the distinctive features of higher education and this requires a careful evaluation of how and what kind of solution can be adopted [10].

The demand for higher education in Saudi Arabia is growing steadily. But the quality of higher education is a growing concern for Ministry of Higher Education [11]. The rapid growth of the young population in Saudi Arabia requires the universities to improve their ICT resources as soon as they can to provide the students and the academics with the ICT resources they need to enhance their teaching and learning experience [12]. This is further bolstered by the fact that cloud-computing resources can be scaled dynamically thereby provide non-restricted computing power for students as well as the academic. There is a need for agile, blended and flexible way to enhance the teaching and learning process to promote good quality research and job opportunities [13]. In Saudi higher education, several studies revealed a positive attitude for students, faculty, and university administrations toward the use of internet-based cloud services in Saudi Arabia [14]. However, despite the benefits cloud services can add to the universities ICT and the positive attitude towards the cloud usage in the Saudi Universities, the migration rate of cloud computing is still in the early stages, this due to the fact that the migration process to the cloud may not be an easy task, As There is a wide range of challenges quoted in the literature including infrastructural, cultural and organizational factors that impede a successful IT project deployment in Saudi organizations [15]. Therefore, this proposed framework is aimed to investigate the factors that will affect the success of the migration project to the cloud.

\section{THE PROPOSED FRAMEWORK}

Critical Success Factors (CSFs) are defined by many researchers in the past but it was introduced first by Rockart in 1978 [16]. In this study the CSFs can be defined as (Those enablers that should be guaranteed by university for successful migration of their traditional ICT educational services to the cloud based services). The proposed framework is constructed to examine the important success factors that will enable the universities IT decision makers and Staff to migrate to the cloud. The framework integrates cultural aspects related to the success factors for implementing ICT projects in the Saudi higher education context along with redefined success factors from the characteristics of cloud computing paradigm (Privacy, Security, Interoperability, Internet bandwidth and Service Level Requirements) [2]. The research conceptual framework has two CSFs categories: Technological CSFs and Organizational CSFs as Shown in Figure 1.

\section{A. Technologiacl CSFS}

This category illustrates the technological aspects that can facilitate the success of the migration process to the cloud.

- Reliability: The University cloud-based services should be reliable and continuously available by providing redundant services, but the possibility still exists that the system could crash and leave clients with no way to access their saved data. Many existing cloud infrastructures leverage commodity hardware that is known to fail unexpectedly. A loss of Internet connectivity anywhere between a university customer and their cloud provider's network will cause interruptions of varying severity. It is important for the service to be reliable, if it is available. So without availability, reliability cannot be achieved. A cloud service should first be available in order to be reliable [5], [17]

- Interoperability: A universal set of standards and interfaces has not yet been defined for cloud based services, resulting in a significant risk of vendor lockin. Higher education institutions should make sure that the Cloud based IT solutions must be interoperable and compatible between different providers; 24/7 access to secure, reliable networks; and the ability to create, deliver, and share content campus-wide on any number of devices [18].

- Security and Privacy: Privacy and security are the top concerns for higher educational institutions planning to adopt cloud computing, due to the migration of sensitive data such as students' records, Researchers' Patents and Intellectual properties outside campus walls. Hence the importance of security and information privacy within University IT environment is crucial [5].

- Disaster recovery: Saudi universities should ensure data recovery and business continuity back up plans, particularly regarding what they are responsible for during a disaster affecting their data centers. Universities have indirect administrative responsibility for the security of their data and applications and are accountable for data breaches and disaster recovery [6], [9].

- Network Bandwidth: Cloud computing is a stateless system, as is the Internet in general. In order for communication to survive on a distributed system, it is necessarily unidirectional in nature. Most of remote requests used in the cloud is through HTTP messages like PUT and GET. The HTTP requests reach the provider and the service provider then sends a response. Low bandwidth would increase the latency of communications and the service would become very slow, if bandwidth is not increased. Therefore, Saudi universities should increase the Internet bandwidth in order to provide good cloud-base services to their stakeholders. 


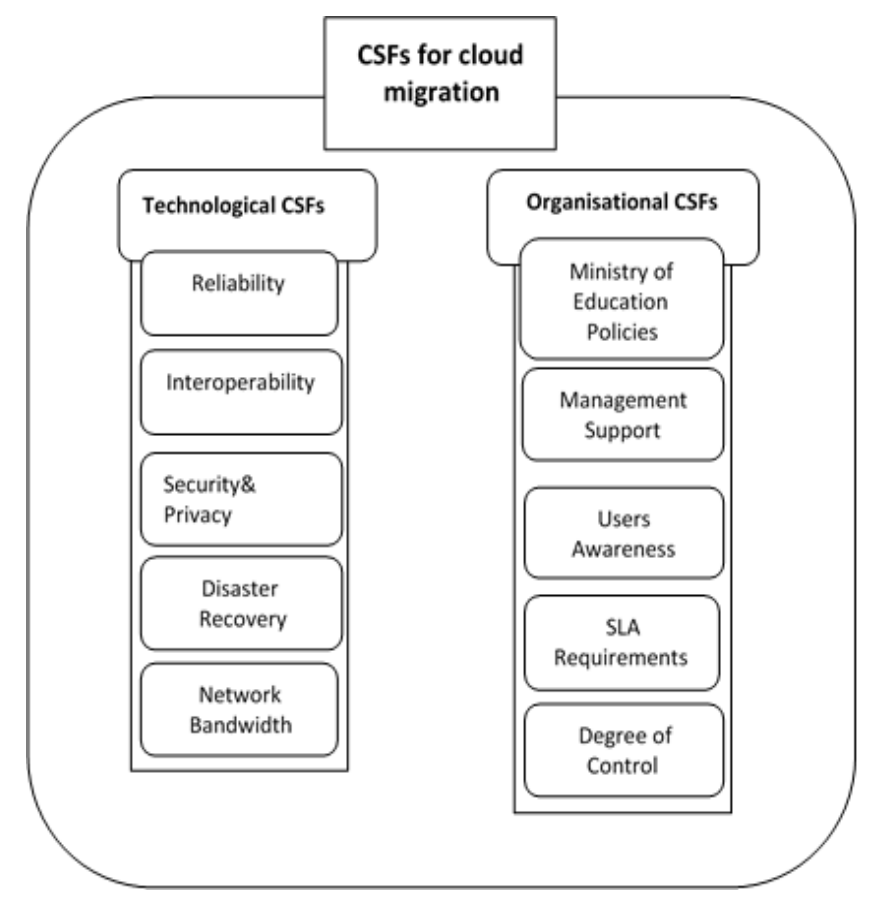

Figure 1.Cloud Migration Framework

\section{B. Organizational CSFs}

This category describes the aspects that are related to University culture and operational roles, which can contribute to the success of the migration process to the cloud.

- Ministry of Education Policies: Since cloud computing is a relatively new IT Paradigm, it will require changes to be made in Ministry of Higher Education policies and regulations and comply with legislations in Saudi government to ensure the safety of stakeholders' information. Saudi universities need to improve data policies in order to protect their sensitive information. This involves developing institution-wide cloud policies to help the institutions select the right sourcing and solutions that comply with the regulations in Saudi Arabia [19].

- Top Management Support: From a strategic perspective, the successful implementation of cloud solutions in Saudi Arabia depends on the capabilities of top leadership or management to drive the change from traditional deployment to cloud adoption through an official pro-cloud strategy. The decision makers' awareness and consensus is vital. Their support will ensure what cloud services are needed and what type of cloud deployment is best for higher education settings. In order to do that the decision makers have to understand the benefits of cloud-based services, the value they can add to the educational services and how to migrate to cloud computing environment.

- Users' awareness: Successful implementation of any new technology requires proper plan to educate and increase the awareness of the stakeholders dealing with the technology and how to develop cloud solutions to serve the educational entities. Therefore, Saudi university IT department should provide their IT staff with training session on how to run cloud-based services and then introduce the cloud computing services to their stakeholders (academics and Students) and provide them with the guide needed in order to use the cloud services properly [20]. The motivation of academics to acquire the required competencies and to make use of cloud based IT for innovation and research is greatly influenced by encouragement from higher authorities and decision makers of Saudi universities. Saudi Higher Education institutions should offer incentives for their people to access cloud based services within a well-defined institutional framework. University decision makers and CIOs should make cloud solutions a part of personal work routines and teaching processes [20].

- Customizable SLA requirements: Saudi Universities need to be able to ensure that the service provider will continue to be there, even in face of changing market. Service level agreements (SLAs) are the contracts between the users of cloud services and the provider and it contains the expected uptime and performance of those services. Universities should consider those measurements and prepare list of customized requirements for each services they use and it needs to collect each department requirements in order to indicate them in the SLA to cover the end-user experience and the customer's operations [10].

- Degree of Control: The amount of control that the user has over the cloud environment varies greatly. In traditional IT environment, the consumer had full control over the services accessed. But the same is not true for the cloud services. For that reason, there is loss of control when universities migrate to the cloud, and it is the duty of the university $\mathrm{CIO}$ or management to make sure that the control is given to the right provider or decide what should be under their control and what can be migrated [5], [7].

\section{CONCLUSION}

Cloud computing is an ICT paradigm to deliver IT services to users as utility over the Internet. The cloud paradigm is well known for its scalability, which could provide direct and immediate benefits to rapidly expanding higher education organizations' services. Moreover, cloud computing for higher education institutions can provide flexible, on demand resources to multiple users at any time based on the share of services used over a Pay As You Go model. However, despite the aforementioned advantages of cloud services, the migration process to cloud based services within the Saudi context faces many challenges and these challenges vary according to the cultural aspects of the technology, organization, legislation and their requirements and infrastructure. The aim of this paper is to form a conceptual framework in order to investigate the most CSFs that can contribute towards successful migration to the cloud in the Saudi higher education settings. 


\section{FUTURE WORK}

Therefore, as this is an ongoing research, the future work will be concentrated on reviewing and confirming the proposed CSFs by utilizing the sequential methodological triangulation approach. The cross confirmation of the framework will involve IT interviews and online questionnaire with experts working in the deanship of Information Communication at different Saudi Universities.

\section{ACKNOWLEDGMENT}

We acknowledge the award of University of Jeddah scholarship to Abdulrahman Alharthi and the Saudi Arabian Cultural bureau in London (SCAB) for allowing the research to be funded and undertaken.

\section{REFERENCES}

[1] R. Buyya, R. Buyya, C. S. Yeo, C. S. Yeo, S. Venugopal, S. Venugopal, J. Broberg, J. Broberg, I. Brandic, and I. Brandic, "Cloud computing and emerging IT platforms: Vision, hype, and reality for delivering computing as the 5th utility," Futur. Gener. Comput. Syst., vol. 25, no. 6, p. 17, 2009.

[2] A. Alharthi, F. Yahya, R. J. Walters, and G. B. Wills, "An Overview of Cloud Services Adoption Challenges in Higher Education Institutions," Closer2015. pp. 102-109, 2015.

[3] V. Benson and S. Morgan, "Student Experience and Ubiquitous Learning in Higher Education: Impact of Wireless and Cloud Applications," Creat. Educ., vol. 04, no. 8, pp. 1-5, 2013.

[4] M. Alabbadi, "Cloud computing for education and learning: Education and learning as a service (ELaaS)," 14th Int. Conf. Interact. Collab. Learn., no. September, pp. 589-594, 2011.

A. Alshwaier, "A New Trend for E-Learning in KSA Using Educational Clouds," Adv. Comput. An Int. J., vol. 3, no. 1, pp. 8197, 2012.

[6] Cisco, "Cloud Computing in Higher Education : A Guide to Evaluation and Adoption," 2011.

[7] N. Sultan, "Cloud computing for education: A new dawn?," Int. J. Inf. Manage., vol. 30, pp. 109-116, 2010.
M. Odeh, K. Warwick, and O. Cadenas, "Major Differences of Cloud Computing Adoption in Universities : Europe vs . Middle East," vol. 5, no. 12, pp. 948-952, 2014.

[9] B. Wheeler and S. Waggener, "Above-Campus Services: Shaping the Promise of Cloud Computing for Higher Education.," Educ. Rev., vol. 44, no. december 2009, p. 10, 2009.

[10] Cisco, "Cloud 101: Developing a Cloud-Computing Strategy for Higher Education," October, 2012. .

[11] K. M. Al-Ajmi, "Quality and emoployability in higher education: the case of Saudi Arabia," 2011

[12] A. Aljabre, "An Exploration of Distance Learning in Saudi Arabian Universities: Current Practices and Future Possibilities," Int. J. Instr. Technol. Distance Learn., vol. 9, no. 2, p. 75, 2012.

[13] A. Q. Naif Jabil, "The Benefits and Barriers of E-learning in Higher Education in Saudi Arabia," 2013. .

[14] G. W. Nouf Alkhater, Robert Walters, "An Investigation of Factors Influencing an Organisation's Intention to Adopt Cloud Computing," in International Conference on Information Society, 2014.

[15] F. Alfaadel, M. Alawairdhi, and M. Al-Zyoud, "Success and failure of IT projects: a study in Saudi Arabia," in Proceedings of the 11th WSEAS international conference on Applied Computer and Applied Computational Science, 2012, pp. 77-82.

[16] G. Carroll and J. Delacroix, "The changeing role of the Inforamtion System executives: A critical success factors perspective," 1982.

[17] A. Shakeabubakor, "Cloud Computing Services and Applications to Improve Productivity of University Researchers," Int. J. Inf. Electron. Eng., vol. 5, no. 2, pp. 153-157, 2015.

[18] Educause, "Shaping the Higher Education Cloud," Readings, 2010.

[19] Z. Krieger, "Saudi Arabia puts its billions behind Western-style higher education," Chron. High. Educ., pp. 1-6, 2007.

[20] M. A. S. Al-Shehri, "A virtual university model for higher education in Saudi Arabia," 2013. 